\title{
Advanced Techniques for Removal of Retrievable Inferior Vena Cava Filters
}

\author{
Bogdan Iliescu $\cdot$ Ziv J. Haskal
}

Received: 14 February 2011/Accepted: 22 May 2011/Published online: 15 June 2011

(C) Springer Science+Business Media, LLC and the Cardiovascular and Interventional Radiological Society of Europe (CIRSE) 2011

\begin{abstract}
Inferior vena cava (IVC) filters have proven valuable for the prevention of primary or recurrent pulmonary embolism in selected patients with or at high risk for venous thromboembolic disease. Their use has become commonplace, and the numbers implanted increase annually. During the last 3 years, in the United States, the percentage of annually placed optional filters, i.e., filters than can remain as permanent filters or potentially be retrieved, has consistently exceeded that of permanent filters. In parallel, the complications of long- or short-term filtration have become increasingly evident to physicians, regulatory agencies, and the public. Most filter removals are uneventful, with a high degree of success. When routine filter-retrieval techniques prove unsuccessful, progressively more advanced tools and skill sets must be used to enhance filter-retrieval success. These techniques should be used with caution to avoid damage to the filter or cava during IVC retrieval. This review describes the complex techniques for filter retrieval, including use of additional snares, guidewires, angioplasty balloons, and mechanical and thermal approaches as well as illustrates their specific application.
\end{abstract}

Keywords Venous intervention .

Endovascular treatment · Vena cava .

Deep vein thrombosis (DVT) · Pulmonary embolism

B. Iliescu · Z. J. Haskal ( $\square)$

Division of Vascular and Interventional Radiology,

University of Maryland School of Medicine,

22 South Greene Street, GK-214, Baltimore, MD 21201, USA

e-mail: ziv2@mac.com

\section{Introduction}

Inferior vena cava (IVC) filters have proven valuable for the prevention of primary or recurrent pulmonary embolism in selected patients with or at high risk for venous thromboembolic disease. Their use has become commonplace, and the numbers implanted increase annually. During the last 3 years, in the United States, the percentage of annually placed optional filters, i.e., filters than can remain as permanent filters or potentially be retrieved, has consistently exceeded that of permanent filters [1-3]. In parallel, the complications of long- or short-term filtration have become increasingly evident to physicians, regulatory agencies, and the public [4-14]. Among these complications are caval thrombosis, extension of lower-extremity deep vein thrombosis (DVT) [13], caval or adjacent vessel perforation (e.g., aorta, lumbar artery, renal artery, common iliac artery) [15-23], penetration of adjacent viscera (e.g., duodenum, liver parenchyma, pancreatitis) [17, 2427], embedding within adjacent bony structures [15, 28, 29], whole or partial migration, device fracture, and embolization [15, 30-41]. Lethal complications have occurred [32, 42]. Furthermore, although caval filters have shown an initial benefit in decreasing recurrent pulmonary embolism, there may be no difference in the long-term survival rate of patients with and without continued caval filtration [2, 5, 43-46]. In August 2010, the United States Food and Drug Administration released an initial communication in response to the filter-related adverse events recommending the removal of retrievable IVC filters as soon as their protection from pulmonary embolism is no longer deemed necessary. It placed this responsibility with both "implanting physicians and clinicians responsible for the ongoing care of patients with retrievable IVC filters" [47]. 
It becomes logical that if an optional filter carries no greater risks than a permanent one, that it becomes the primary device used; this is reflected in the aforementioned market trends $[2,3,5]$. As filter retrieval becomes less of an "optional" event, dedicated physician and practice mechanisms to enhance retrieval rates will be required. Current published reports describe a broad range of retrieval rates from 1.0 to $40.5 \%$ [3, 48-55]. Minocha et al. showed the value of this type of a proactive program: Once implemented, IVC retrieval rates increased from 29 to $60 \%$ [56]. With this growing awareness and responsibility, physicians will need to be prepared to perform straightforward as well as advanced and highly complex filter retrievals. Herein we review some of the expanded approaches to filter retrieval.

\section{IVC Filters and Dwell Times}

Caval filters continue to be an area of active product development and evolution. Because their designs vary, so do retrieval times, techniques, and potential complications. This emphasizes the need for methodical reporting of adverse events through governmental databases, such as MAUDE (Manufacturer and User Facility Device Experience), or national societal registries, such as the CIRSE and imminent Society of Interventional Radiology caval filter retrieval registries. One of the more common unifying filter designs is the "cone" or "umbrella," placed with the apex directed cephalad. A number of filters share this design, including the Günther Tulip and Celect filters (Cook Medical, Bloomington, IN); the Recovery G2, G2X, and Eclipse filters (Bard Peripheral Vascular, Tempe, AZ), the Option filter (AngioTech, Vancouver, BC); and ALN filter (ALN Implants Chirurgicaux, Ghisonaccia, France). These are removed by using a jugular vein approach to snare the apical "hook" or structure with a dedicated removal device or one of the many available general endovascular snares. The OptEase filter (Cordis Endovascular, Warren, NJ) has a "double-basket" trapezoidal shape, similar to the permanent TrapEase filter (Cordis Endovascular, Warren, NJ), with the exception of a single set of unidirectional fixation hooks. Its retrieval hook is caudal, warranting a femoral snare approach. These devices are inserted and removed safely with a high degree of technical success [2, 5, 50, 52, 57-61].

The timing for safe and uncomplicated retrievability of an optional IVC filter cannot be universally determined. It depends on the filter design, its orientation at the time of retrieval, caval shape, tissue response, and, finally, the operator's comfort with potentially more complex retrieval maneuvers. Several investigators have described successful uncomplicated IVC filter retrieval after long dwell times.
Binkert et al. reported removal of Recovery filters after a mean of 254 days (range 181-419) [57]. Günther Tulip filters have been similarly retrieved at prolonged intervals, e.g. 317 and 475 days $[62,63]$ but with a decreasing success rate as dwell times increase [64]. Recently, Lynch reported removal of a filter at 3006 days after implant [65]. Although filter retrieval histology is relatively underreported, adherence of acute clot and fibrin to the devices, later becoming more mature fibrous tissue and neointimal hyperplasia, has been described [66].

\section{IVC Filter-Retrieval Techniques}

There is no defined algorithm for preidentifying more complex retrievals, nor are there certain filters or patients that would be routinely predisposed to them. At present, there is neither suggested mandate nor consensus regarding a need for preretrieval imaging to identify high-risk patients. Because these would likely require additional radiation due to plain radiographs or computed tomography (CT) scans, prescreening is unlikely to be routinely used or indicated. Fortunately, most retrievals are usually uneventful, even in the setting of an extruded leg residing in the paracaval tissues. If during the course of the retrieval complexity is identified (e.g., suspected transcaval component extension), then several approaches can provide additional useful information, particularly CT; or, increasingly, cone-beam angiographic CT [24, 67]; or perhaps rotational angiography [68, 69]. CT has shown excellent ability to demonstrate filter-leg penetration of the cava wall; in one series, it was demonstrated in $85.9 \%$ of 64 filter retrievals, and $89 \%$ of these filters were retrieved [67].

When the filter's apex or "hook" cannot be engaged using the designated retrieval cone or one of the many retrieval snares, then adjunct techniques become useful. Caution is required when employing these techniques to avoid filter distortion, damage, dismemberment, or downstream embolization of the filter or filter components. The choice of secondary retrieval technique must be tailored to each situation.

\section{Realignment Technique}

\section{Loop Snare With Single Access}

When the filter is not aligned in the longitudinal axis of the IVC, it may be difficult to engage its apex with an endovascular snare or retrieval cone advanced through its original straight catheter. Exchanging this catheter for a curved or angled angiographic or guiding catheter may allow sufficient redirection of the snare toward the filter 
apex to allow it to be prolapsed between the filter and caval wall (Fig. 1). The filter can thus be grasped and realigned. This simple maneuver may allow the filter to be directly removed with that snare or pulled into a more central orientation so that the retrieval cone may then be used (Fig. 2). Alternatively, a tip-deflecting wire (Cook, Bloomington, IN) can be used to attempt filter "realignment." The wire is placed adjacent to the tilted filter and used to deflect the apex of the filter into the lumen of the IVC. Conventional snare or cone retrieval commences thereafter $[24,70]$.

\section{Stiff Wire-Displacement Technique}

\section{Tilted Filter-Straightening Single Access}

In cases in which a tilted filter's apex cannot be conventionally engaged, it can often be sufficiently displaced away from the caval wall by advancing a stiff straight (or intentionally bent) wire between the filter apex and the caval wall (Fig. 3). This single-access approach allows over-the-wire advancement of the retrieval cone into the IVC, allowing the cone to grasp both the filter and wire together. Once both have been drawn partly or wholly into the sheath, the wire can be released or removed in toto with the filter (Fig. 4). Alternatively, a coaxial loop snare can be advanced over the wire in a "monorail" fashion, similarly grasping the filter apex and wire together, and removing both simultaneously [71]. This "stiff man" technique can be used from the jugular approach for cone-shaped IVC filters and the femoral approach for trapezoidal filters [72].

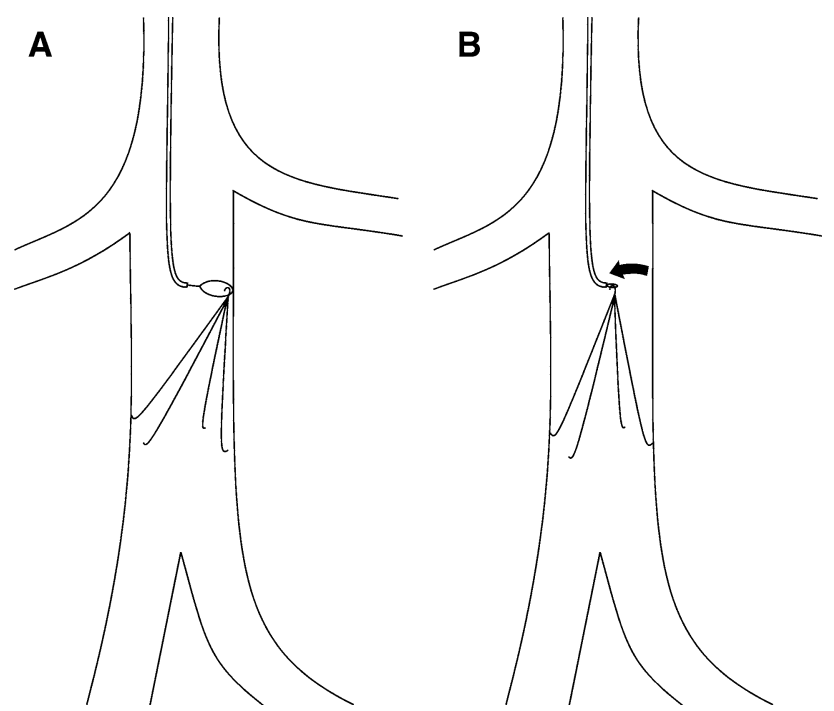

Fig. 1 Realignment technique (loop snare with single access). A Curved guiding catheter is used to redirect the snare toward the filter apex. B Filter apex is grasped with the snare and realigned with the axis of the cava (curved arrow)

\section{Dual-Access Technique}

Wire and Snare With Dual Access

In cases in which the aforementioned single-access approach fails to displace the tilted filter, a through-andthrough "flossing" approach may increase the distraction force on the tilted nonembedded or mildly epithelialized filter. Jugular and femoral vascular access are established. The stiff wire is introduced from the femoral or jugular approach, directed between the filter apex and the IVC wall, and snared from the alternate approach (Fig. 5). Wire traction is simultaneously applied in caudal and cephalic directions. One cautionary note: The through-and-through wire should be protected by long covering sheaths or catheters to prevent entry or pelvic vein lacerations during this maneuver (i.e., "cheese-slicing"). The dual-access approach can release the filter apex from the IVC wall. The snare, originally introduced through the direction of ultimate retrieval, would immediately be used to remove the repositioned filter.

\section{Balloon-Displacement Technique}

In cases in which the tilted embedded apex cannot be released by the previously described techniques, the filter can be shimmied away from the cava using an interposed angioplasty balloon (Fig. 6). The balloon is then inflated between the apex of the filter or its embedded struts, thus displacing it from the caval wall [73]. The balloon displacement technique can be used with or without a through-and-through guidewire. This form of "blunt dissection" was reported as useful by Lynch et al. [74] in releasing 8 of 10 severely titled filters out of 257 retrievals.

\section{Sling Technique}

Wire Loop-and-Snare Single Access

A single-access "sling" approach can be useful in releasing a filter whose apex is embedded. For this technique, a short-radius reverse-curve catheter is positioned below the retrieval zone of the filter and used to direct a guidewire backwards in a "U-turn" fashion. A para-axial snare, placed alongside through the same outer sheath, is used to grasp the guidewire and exteriorize it. The maneuver creates a sling around the filter. The sheath is then advanced to its apex, and traction is then applied to both ends of the wire to pull it from the wall. The filter can then withdrawn into the sheath and removed (Fig. 7). Rubenstein et al. [75] used this approach in eight tilted IVC filters that could not 

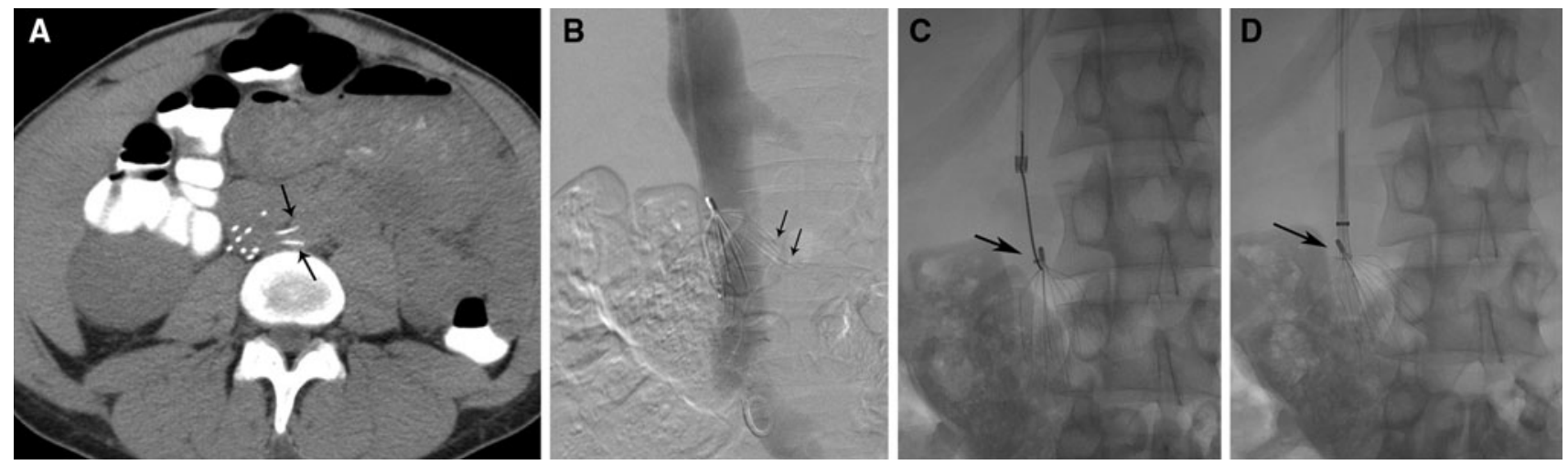

Fig. 2 A 37-year-old man underwent IVC filter placement after developing postoperative DVT. Twenty-five months later, he presented for filter retrieval. A CT scan demonstrates two filter legs penetrating the aorta (arrows). B Inferior vena cavagram

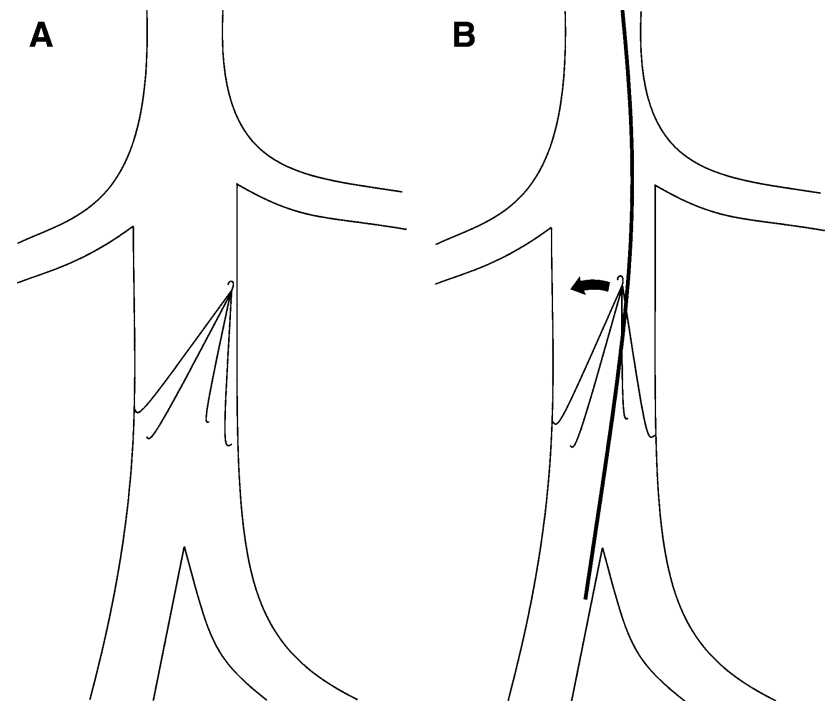

Fig. 3 Stiff wire-displacement ("stiff man") technique. A Tilted filter resides with apex adjacent to the cava wall. B A stiff wire is advanced between the filter apex and cava wall, displacing the filter apex toward the cava lumen (curved arrow)

be removed using standard techniques. Turba described its use for removal of a filter that was tilted to $90^{\circ}$ [24]. We recommend the use of a nitinol wire for the sling wire due to its super elastic properties and kink resistance.

\section{Sandwich Technique}

\section{Parallel Wire and Dual-Sheath Technique}

Occasionally, a recalcitrant filter can be freed or untilted by being sandwiched between two sheaths (Fig. 8). In this approach, the guidewires are passed through a guiding catheter (e.g. 6F) along either side of the filter's "nose." demonstrates multiple filter legs outside the vena cava (arrows). There is no caval thrombus. C The filter apex is grasped using a loop snare (arrow) and is "realigned." D A retrieval cone (arrow) is then used to remove the filter

Both wires are snared and exteriorized through the opposing respective sheaths. The long catheter and sheath are advanced into snug contact against the filter, after which upward or downward force can be selectively and repetitively applied to "rock" the filter free (Fig. 9). This technique can be attempted with a single wire; however, we recommend the use of parallel wires to better encapsulate the "neck" of the filter. The parallel wire approach might also minimize filter disassembly during the traction. The retrieval sheath is then used to remove the disengaged filter. A variation of this technique has been described by Owens et al. [76].

\section{Dissection Technique}

\section{Rigid Bronchoscopy Forceps, Thermal, Etc}

In cases in which the filter is densely embedded in the IVC wall, rigid bronchoscopy forceps (Fig. 10) have been used to nibble at, or "micro-dissect," the tissue surrounding the filter tip and potentially grasp and remove it [77-79]. This technique has been successfully used for both cone-shaped and trapezoidal filters [79]. This technique is naturally more invasive than simpler snare and displacement techniques because of the risk of vessel perforation or rupture [78]. Although no major complications were reported in a series of 20 successful retrievals, the need for this approach may warrant patient referral to centers that have gained experience with it and other third-order retrieval techniques. Similarly, Kuo et al. described the safe use of an endovascular laser sheath as a thermal dissection tool to free embedded filters. Their successful technique was described in a canine model [80] and subsequently in human applications [81, 82]. 

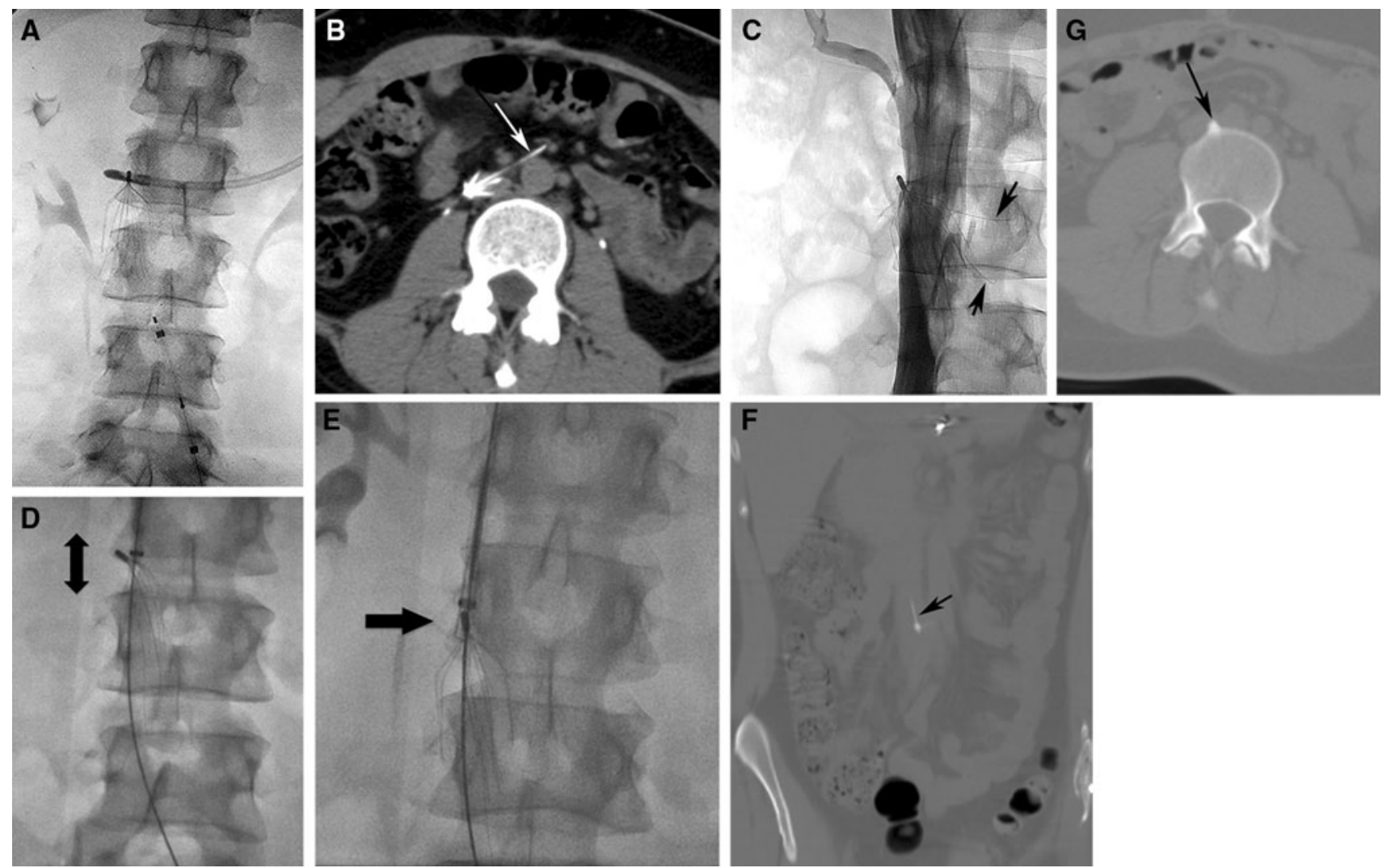

Fig. 4 A 24-year-old woman received an IVC filter caval after a motor vehicle accident and extensive injuries. She presented for filter retrieval 18 months later. A Abdominal radiograph from the time of initial filter placement demonstrates the filter to be in desired axial alignment with the cava. B CT scan demonstrates a filter leg perforating through the cava wall and residing anterior to the aorta (arrow). C Fluoroscopic image obtained at the time of filter retrieval shows its legs protruding beyond the cava lumen (arrows).

D Fluoroscopic image demonstrating the filter neck grasped with the retrieval cone. Using a cranio-caudal "rocking" motion (double arrow), the apex is released from the caval wall. $\mathbf{E}$ The removal cone is then used to grasp the apex of the filter (arrow) and remove it. (F) CT image demonstrates a remaining dismembered filter leg (arrow). G Focal vertebral-body sclerosis and exophitic calcification developed around the embedded filter leg tip (arrow)

Fig. 5 Dual-access technique (wire and snare with dual access). A Wire is introduced by way of jugular access and directed between filter apex and cava wall with the aid of a curved-tip guiding catheter. B The wire is snared by way of femoral approach. C Wire traction is applied simultaneously in caudal and cephalic directions (straight arrows) resulting in displacement of the filter apex from the cava wall (curved arrow)
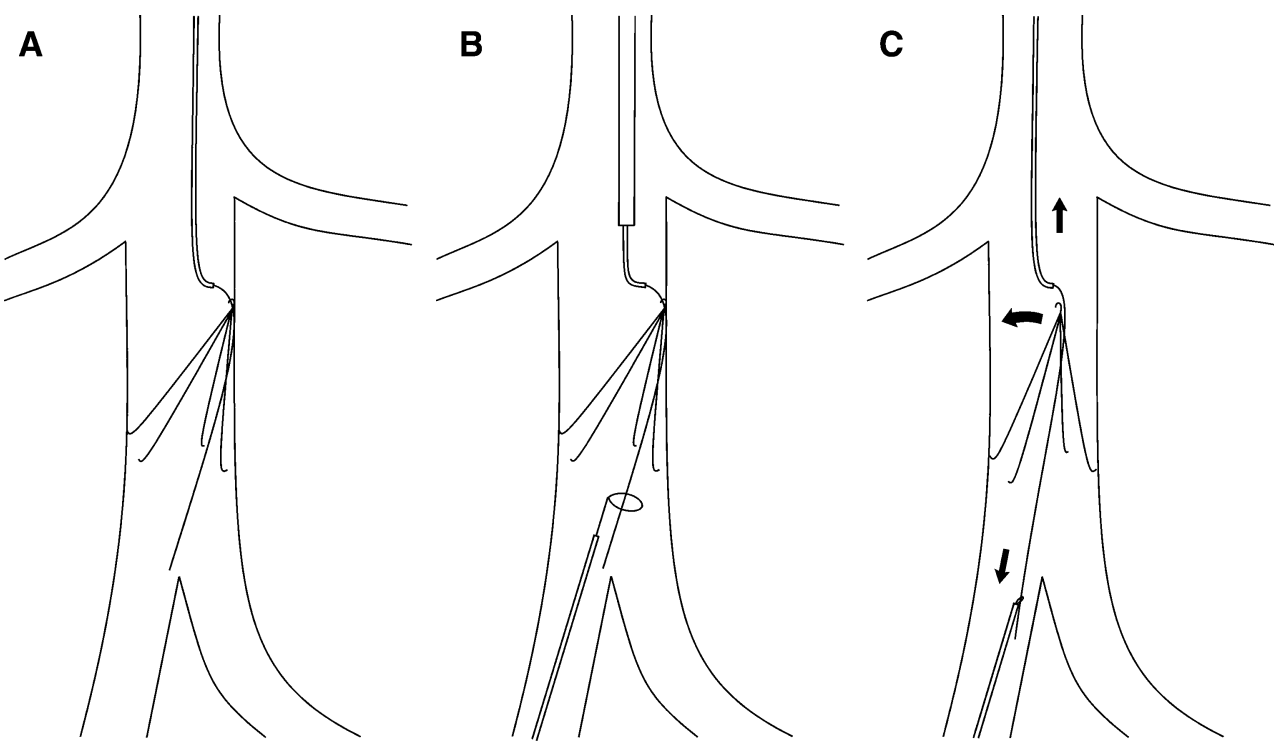

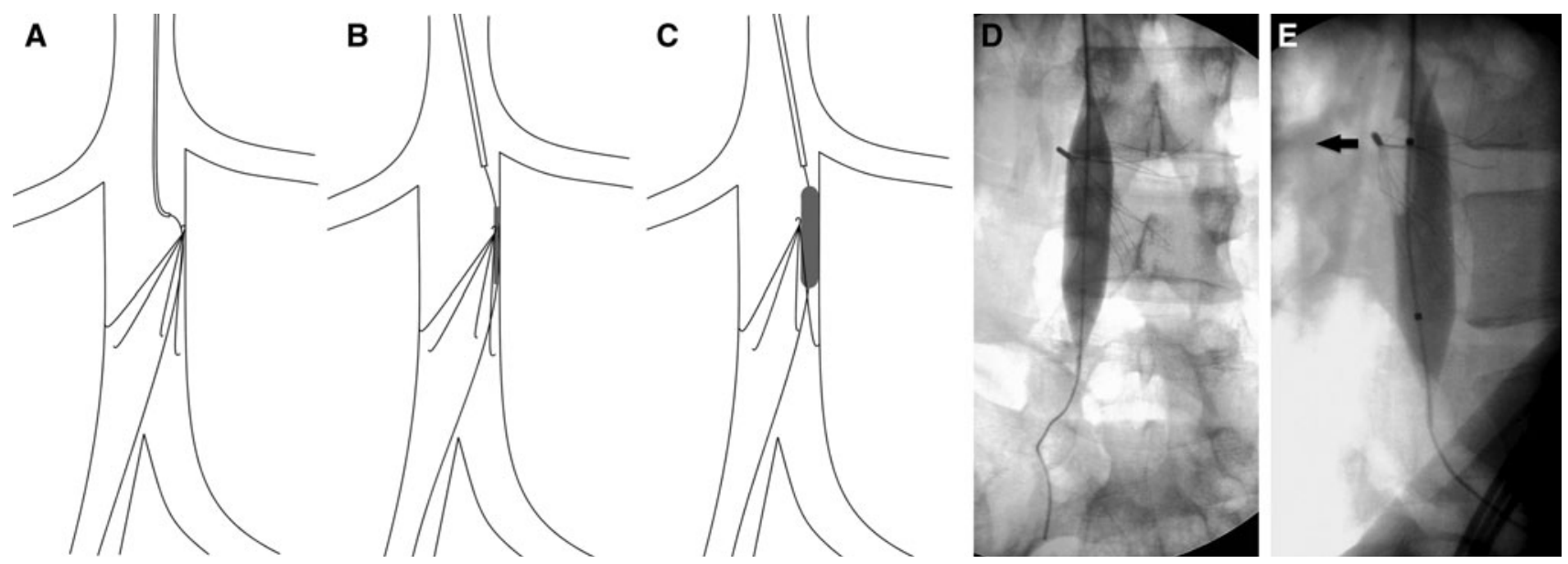

Fig. 6 Balloon-displacement technique. A A curved-tip guiding catheter used to direct the wire between filter apex and cava wall. B Angioplasty balloon is positioned at the level of the filter apex. C The balloon is inflated to displace the filter from the cava wall. D A 19-ear-old multiple trauma patient received a retrievable IVC filter for pulmonary embolism prophylaxis. He presented 21 months later for filter removal. Fluoroscopy demonstrates a tilted filter with leg extrusion beyond the cava lumen. Conventional retrieval techniques proved unsuccessful. A $10 \times 40-\mathrm{mm}$ angioplasty balloon was positioned posterior to the filter apex and used to displace it anteriorly, thus freeing the embedded device. E A lateral image of this maneuver shows the anterior displacement of the filter apex from the cava wall with the balloon (arrow). The filter apex seen through the intraballoon air bubble. The filter was then removed successfully with a retrieval cone (not shown)

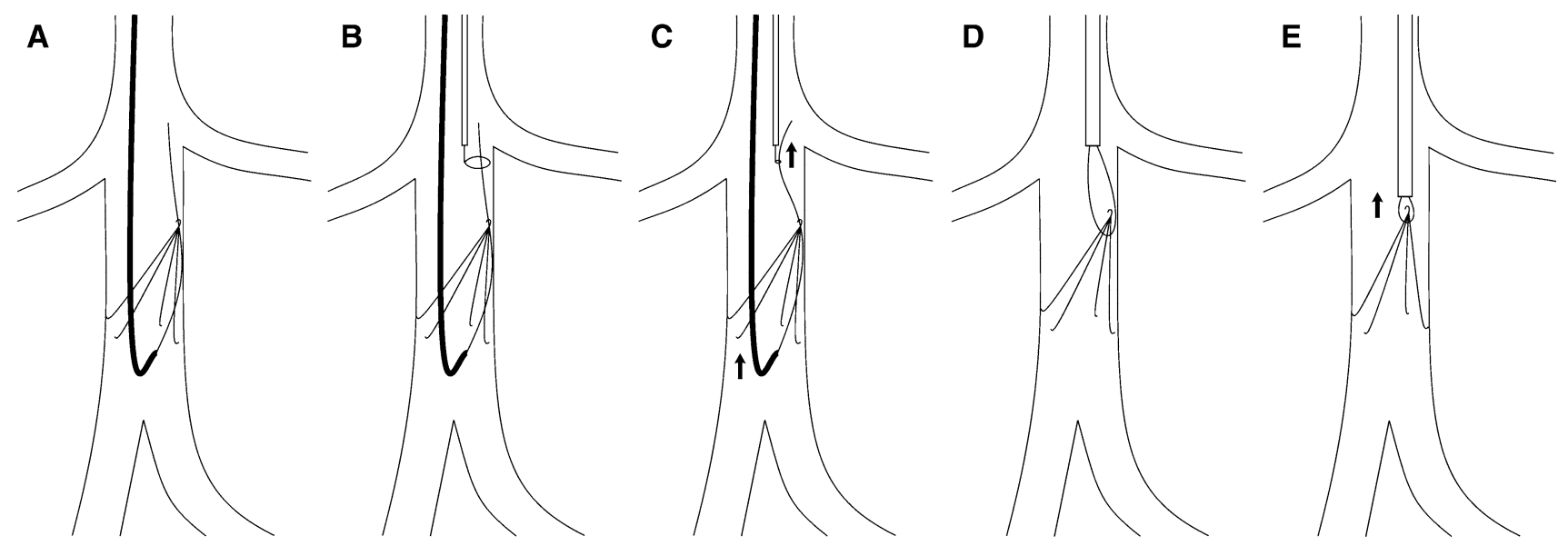

Fig. 7 Sling technique (wire loop and snare single access). A A small-radius reverse-curve catheter is positioned below the filter apex and used to direct a guidewire in a retrograde direction. B A paraaxial snare is introduced through the same sheath and used to grasp the wire. $\mathbf{C}$ The catheter and snare with the wire grasped are then

\section{Retrieval of Migrated IVC Filters}

Caudal migration of IVC filters is a commonly reported occurrence $[60,83]$. In one series, of the patients evaluated for IVC filter removal, as many as $52 \%$ of the filters had migrated ( $12 \%$ moved $>20 \mathrm{~mm}$, and $40 \%$ moved $<20 \mathrm{~mm}$ ) [60]. A small number of cases of caudal migration with caval perforation and successful removal have been described, without major complications, e.g., in a patient with only self-limited abdominal pain and requiring no withdrawn into the vascular sheath (arrows) externalizing both wire ends. D This maneuver results in the creation of a "sling" around the filter. $\mathbf{E}$ The sheath is advanced to the filter apex and traction is applied to both ends of the wire to remove the filter (arrow)

treatment [83]. Cranial migration within the IVC occurs less frequently [60]. In most cases, conventional removals were performed; in one series, only $8.9 \%$ of these downstream caval migrations required advanced retrieval techniques [60].

The most feared filter migrations are cardiac or pulmonary. These events have been described, either as total or fragmentary migration, with nearly every model of filter. Although these events may be asymptomatic, major (including lethal) complications have been described, 

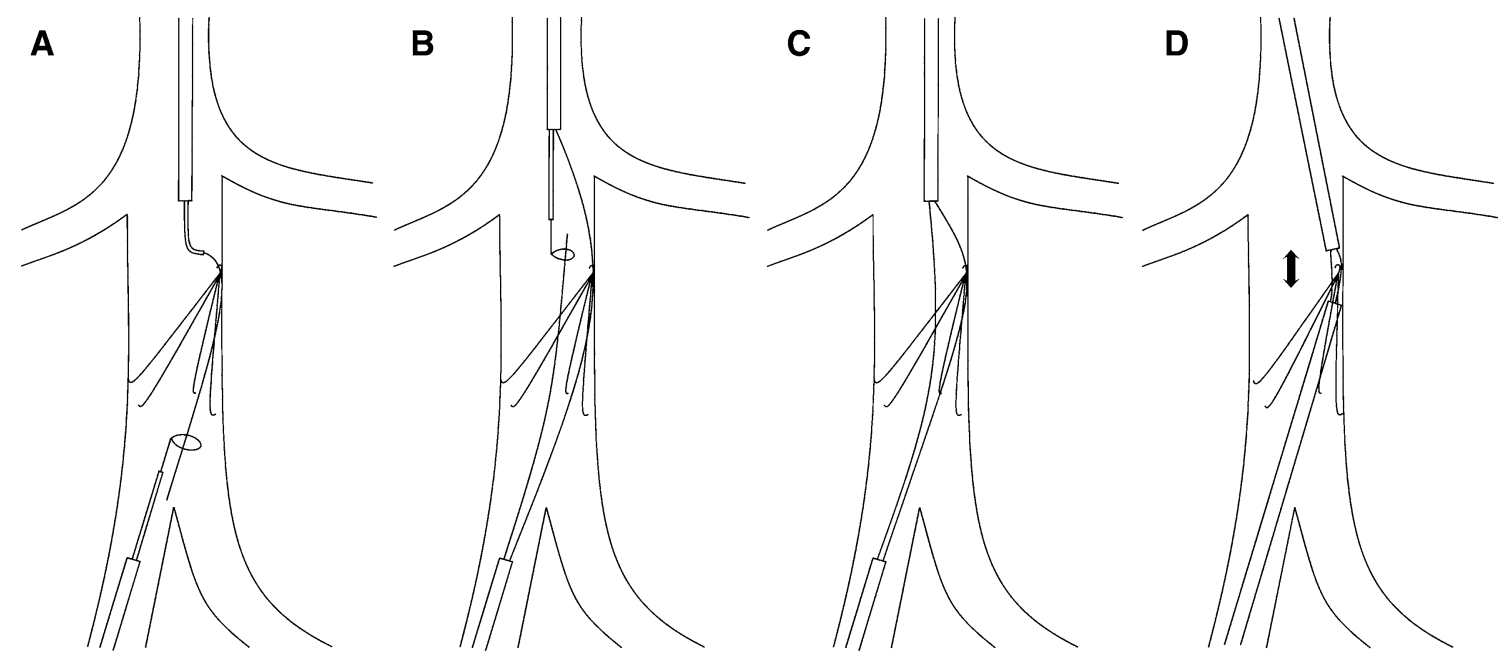

Fig. 8 Sandwich technique (parallel wire and dual sheath technique). A Femoral and jugular access is achieved: Wire directed between filter and caval wall by way of jugular access, then snared from the femoral access and externalized. B Wire introduced on opposite side of filter "nose" by way of femoral access and snared by way of

jugular access. C This maneuver results in externalized double wires around the filter "nose." D Sheaths are then advanced adjacent to the filter, and force is applied in cranial and caudal directions (doubleended arrow) to "rock" the filter free
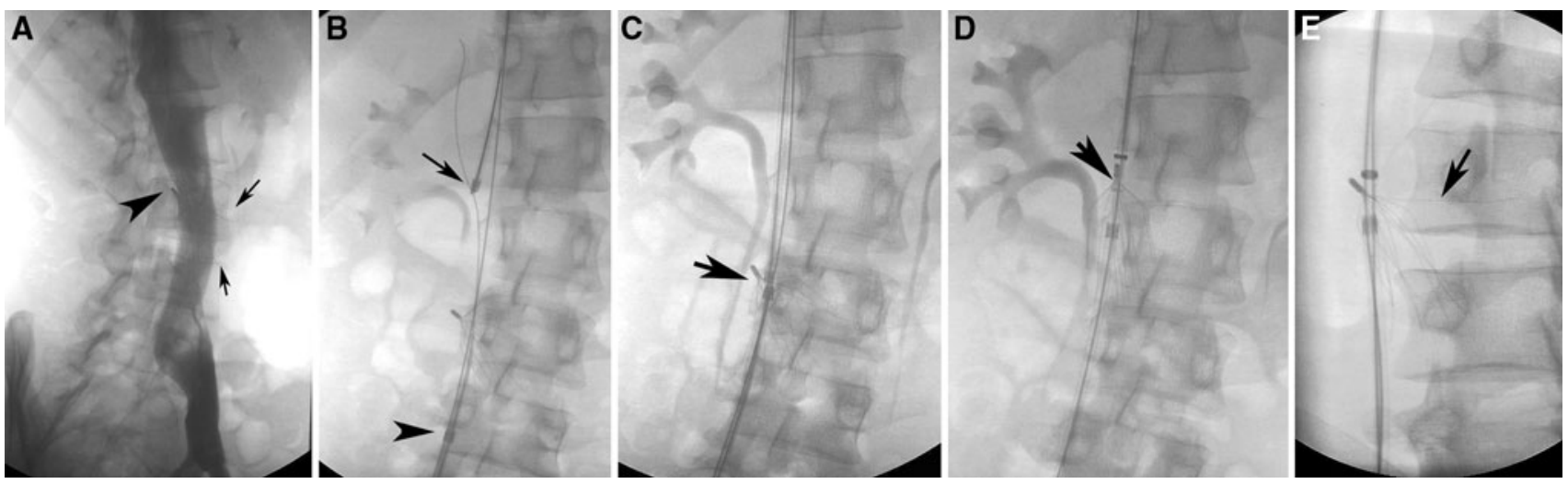

Fig. 9 A Venocavagram obtained at the time of filter retrieval demonstrates the filter apex epithelialized within the cava wall (arrow head) and several legs extruding beyond the cava lumen (arrows). B Wire placed by way of the femoral access sheath (arrowhead) is grasped with a loop snare within a jugular access sheath (arrow). A femoral safety is in place. C Femoral and jugular sheaths are advanced over the single wire to the filter level, thus "sandwiching"

including cardiac tamponade, chamber perforation, myopericarditis, and tricuspid valve damage $[4,32-37,39,40]$. Retrievals in this setting are rarely reported [84, 85], and surgical management is usually undertaken $[35,36,38]$. Bui et al. reported a double-snare technique for percutaneous removal of a G2 IVC filter that had migrated into a patient's right ventricle 3 months after placement. The first snare captured the apex while the second snare was used to restrain the legs with the anchoring hooks, thus facilitating retrieval [37]. Such techniques cannot be considered routine, and most patients require surgical intervention for retrieval. The the filter (arrow) and the filter apex is released into the cava lumen with a cranio-caudal "rocking" motion. D The released filter has been moved cephalad, and the retrieval cone is used to remove the filter (arrow). E "Sandwich" technique is used to retrieve an embedded filter in another patient, with leg extrusion (arrow) beyond the cava lumen, using two wires to stabilize the sheaths

multiplicity of filter hooks, barbs, legs, and risk of disassembly, combined with the potentially embedded state within an atrial or ventricular wall or valve apparatus, should demand guidance exceeding that of fluoroscopy alone. Furthermore, the ability to become entangled within a valve during a retrieval attempt may be difficult to assess with image guidance. In a review of 98 cases of intracardiac or intrapulmonary filter migrations, surgical removal was recommended as the primary approach. Thus, present endovascular options should be reserved for rare cases in which surgery is not an option [35]. 


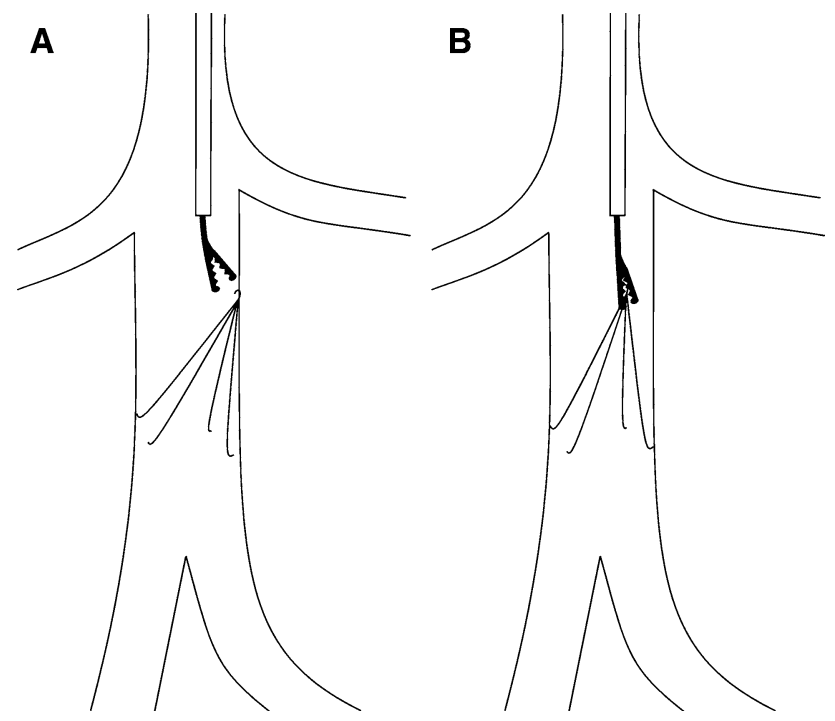

Fig. 10 Dissection technique (rigid bronchoscopy forceps). A Bronchial forceps are directed toward the embedded filter and are used to "micro-dissect" the tissues around the apex. B Forceps are then used to grasp the filter apex and release it form the cava wall

\section{Complications of Filter Retrieval}

Minor complications have been reported with filter retrieval, including transient demonstration of caval wall injury [79]. Most of the literature focuses on the complications attributed to the filter's malpositioning rather than the retrieval per se, e.g. tilt, caval penetration, caval narrowing, and filter fracture [55, 60, 61, 86]. Reported major complications attributed to the actual retrieval are rare $[52,66]$, but recurrent venous thromboembolism after filter retrieval has been described [87]. It should conservatively be assumed that these events may be underreported or might increase with greater numbers of potentially complex retrieval attempts. It is logical that techniques requiring more aggressive maneuvers may prove to have a greater rate of procedure related complications, particularly during learning phases.

One common question concerns the management of ongoing anticoagulation at the time of intended filter retrieval. Schmelzer et al. 2008 [88] described a retrospective review of 54 filters retrieved from 62 fully anticoagulated patients. There were no intraprocedural or postprocedural bleeding complications. They concluded that retrieval of IVC filters can be performed safely in anticoagulated patients. Nevertheless, it seems logical to interrupt anticoagulation at the time of retrieval, particularly because advanced or more aggressive techniques may be required for removal. The use of injectable low molecular-weight heparins allows this to be easily accomplished.

\section{Conclusion}

Retrievable caval filters have increased the pool of candidates for filter placement, in part by holding out the promise of eventual removal. So far, the promise of temporary IVC filter placement has not been broadly fulfilled, as evidenced by the low retrieval rates. Because some of these filters will become increasingly embedded with time, migrate, and/or tilt, one might hypothesize that difficulty of retrieval might grow with longer dwell times. Still, the majority of retrievals are relatively straightforward, and the techniques we review offer a reference for secondorder techniques that may prove increasingly valuable. Undoubtedly new or variant approaches will be described.

During the last 3 years, an average of $>200,000$ annual filters were sold within the United States alone [1]. Endovascular physicians will need dedicated follow-up programs to track their patients and identify appropriate candidates for retrieval. This essential methodical followup will result in an increased retrieval rate as well as the need for physician awareness and expertise for conventional and exotic techniques for IVC filter retrievals. A system for tertiary and quaternary referral for the use of the most advanced techniques may be useful.

Conflict of interest The authors state that there is no actual or potential conflict of interest in relation to this article

\section{References}

1. Inferior Vena Cava Filters (2010) United states market for peripheral vascular devices. iData Research Inc., Vancouver, British Columbia

2. Van Ha TG, Chien AS, Funaki BS et al (2008) Use of retrievable compared to permanent inferior vena cava filters: a single-institution experience. Cardiovasc Intervent Radiol 31(2):308-315

3. Yunus TE, Tariq N, Callahan RE et al (2008) Changes in inferior vena cava filter placement over the past decade at a large community-based academic health center. J Vasc Surg 47(1):157-165

4. Nicholson W, Nicholson WJ, Tolerico P et al (2010) Prevalence of fracture and fragment embolization of Bard retrievable vena cava filters and clinical implications including cardiac perforation and tamponade. Arch Intern Med 170(20):1827-1831

5. Kim HS, Young MJ, Narayan AK, Hong K, Liddell RP, Streiff MB (2008) A comparison of clinical outcomes with retrievable and permanent inferior vena cava filters. J Vasc Interv Radiol 19(3):393-399

6. Nazzal M, Chan E, Abbas J, Erikson G, Sediqe S, Gohara S (2010) Complications related to inferior vena cava filters: a single-center experience. Ann Vasc Surg 24(4):480-486

7. Ingber S, Geerts WH (2009) Vena caval filters: current knowledge, uncertainties and practical approaches. Curr Opin Hematol 16(5):402-406

8. Berczi V, Bottomley JR, Thomas SM, Taneja S, Gaines PA, Cleveland TJ (2007) Long-term retrievability of IVC filters: should we abandon permanent devices? Cardiovasc Intervent Radiol 30(5):820-827 
9. Usoh F, Hingorani A, Ascher E et al (2010) Prospective randomized study comparing the clinical outcomes between inferior vena cava Greenfield and TrapEase filters. J Vasc Surg 52(2): 394-399

10. Hajduk B, Tomkowski WZ, Malek G, Davidson BL (2010) Vena cava filter occlusion and venous thromboembolism risk in persistently anticoagulated patients: a prospective, observational cohort study. Chest 137(4):877-882

11. Patel SH, Patel R (2007) Inferior vena cava filters for recurrent thrombosis: current evidence. Tex Heart Inst J 34(2):187-194

12. Streiff MB (2003) Vena caval filters: a review for intensive care specialists. J Intensive Care Med 18(2):59-79

13. Joels CS, Sing RF, Heniford BT (2003) Complications of inferior vena cava filters. Am Surg 69(8):654-659

14. Wang W, Spain J, Tam MD (2010) Acute abdominal pain after retrievable inferior vena cava filter insertion: case report of caval perforation by an Option filter. Cardiovasc Intervent Radiol [Epub ahead of print]

15. Gupta P, Lopez JA, Ghole V, Rice GD, Ketkar M (2009) Aortic and vertebral penetration by a G2 inferior vena cava filter: report of a case. J Vasc Interv Radiol 20(6):829-832

16. Satya R, Anderson J, Lievano G, Satya RJ (2009) Inferior vena cava (IVC) rupture and retroperitoneal hemorrhage caused by IVC filter migration. J Vasc Interv Radiol 20(8):1102-1104

17. Becher RD, Corriere MA, Edwards MS, Godshall CJ (2010) Late erosion of a prophylactic Celect IVC filter into the aorta, right renal artery, and duodenal wall. J Vasc Surg 52(4):1041-1044

18. Medina CR, Indes J, Smith C (2006) Endovascular treatment of an abdominal aortic pseudoaneurysm as a late complication of inferior vena cava filter placement. J Vasc Surg 43(6):1278-1282

19. Dillon BJ, Alomari AI (2008) Lumbar artery pseudoaneurysm following inferior vena cava filter placement. J Vasc Interv Radiol 19(11):1673-1674

20. Amole AO, Kathuria MK, Ozkan OS, Gill AS, Ozkan EO (2008) Lumbar artery laceration with retroperitoneal hematoma after placement of a G-2 inferior vena cava filter. Cardiovasc Intervent Radiol 31(6):1257-1259

21. Savastano S, Mario B, Dall'acqua J, Mansi G (2010) A right common iliac artery pseudoaneurysm with an iliac-caval arteriovenous fistula: a rare complication of the Recovery vena cava filter. Cardiovasc Intervent Radiol 33(3):667-669

22. Durack JC, Westphalen AC, Kekulawela S, et al. (2011) Perforation of the IVC: Rule rather than exception after longer indwelling times for the gunther tulip and celect retrievable filters. Cardiovasc Intervent Radiol [Epub ahead of print]

23. Morishita H, Yamagami T, Matsumoto T, Takeuchi Y, Sato O, Nishimura T (2011) Endovascular repair of a perforation of the vena caval wall caused by the retrieval of a Gunther Tulip filter after long-term implantation. Cardiovasc Intervent Radiol 34(Suppl 2):S321-S323

24. Turba UC, Glaiberman C, Picus D, Arslan B, Angle JF, Matsumoto AH (2008) Management of severe vena cava filter tilting: Experience with Bard G-2 filters. J Vasc Interv Radiol 19(3):449-453

25. Obmann MA, Gray JL, Sheldon DG, Franklin DP (2010) Duodenal perforation and vertebral body erosion by a Greenfield filter. J Vasc Surg 51(6): 1528

26. Chin BW, Leong RW, Chong AK, Chieng YH, Meredith $\mathrm{C}$ (2006) Inferior vena cava filter eroding into duodenum. Gastrointest Endosc 64(5):817-818

27. Ford ME, Lippert JA, McGraw JK (2010) Symptomatic filter penetration presenting as pancreatitis. J Vasc Interv Radiol 21(4): 574-576

28. Veroux M, Tallarita T, Pennisi M, Veroux P (2008) Late complication from a retrievable inferior vena cava filter with associated caval, aortic, and duodenal perforation: A case report. J Vasc Surg 48(1):223-225
29. Fang W, Hieb RA, Olson E, Carrera GF (2007) Asymptomatic lumbar vertebral erosion from inferior vena cava filter perforation. Cardiovasc Intervent Radiol 30(3):494-496

30. Kalva SP, Athanasoulis CA, Fan CM et al (2006) "Recovery" vena cava filter: experience in 96 patients. Cardiovasc Intervent Radiol 29(4):559-564

31. Emaminia A, Fedoruk LM, Hagspiel KD, Bozlar U, Kron IL (2008) Inferior vena cava filter migration to the heart. Ann Thorac Surg 86(5):1664-1665

32. Shmuter Z, Frederic FI, Gill JR (2008) Fatal migration of vena caval filters. Forensic Sci Med Pathol 4(2):116-121

33. Chandra PA, Nwokolo C, Chuprun D, Chandra AB (2008) Cardiac tamponade caused by fracture and migration of inferior vena cava filter. South Med J 101(11):1163-1164

34. Adair JD, Harvey KP, Mahmood A (2008) Inferior vena cava filter migration to right ventricle with destruction of tricuspid valve: A case report. J Trauma 64(2):509-511

35. Owens CA, Bui JT, Knuttinen MG et al (2009) Intracardiac migration of inferior vena cava filters: Review of published data. Chest 136(3):877-887

36. Galhotra S, Amesur NB, Zajko AB, Simmons RL (2007) Migration of the Gunther Tulip inferior vena cava filter to the chest. J Vasc Interv Radiol 18(12):1581-1585

37. Bui JT, West DL, Pinto C, Gramling-Babb P, Owens CA (2008) Right ventricular migration and endovascular removal of an inferior vena cava filter. J Vasc Interv Radiol 19(1):141-144

38. Janjua M, Omran FM, Kastoon T, Alshami M, Abbas AE (2009) Inferior vena cava filter migration: Updated review and case presentation. J Invasive Cardiol 21(11):606-610

39. Kalavakunta JK, Thomas CS, Gupta V (2009) A needle through the heart: Rare complication of inferior vena caval filters. J Invasive Cardiol 21(11):E221-E223

40. Desjardins B, Kamath SH, Williams D (2010) Fragmentation, embolization, and left ventricular perforation of a recovery filter. J Vasc Interv Radiol 21(8):1293-1296

41. Kassavin DS, Constantinopoulos G, Ansari S (2011) Cardiopulmonary resuscitation and associated anatomic and hemodynamic changes in the vena cava: Risk factors for inferior vena cava filter migration? Cardiovasc Intervent Radiol 34(Suppl 2):S318-S320

42. Haddadian B, Shaikh F, Djelmami-Hani M, Shalev Y (2008) Sudden cardiac death caused by migration of a TrapEase inferior vena cava filter: Case report and review of the literature. Clin Cardiol 31(2):84-87

43. Young T, Tang H, Aukes J, Hughes R (2007) Vena caval filters for the prevention of pulmonary embolism. Cochrane Database Syst Rev(4):CD006212

44. The PREPIC Study Group (2005) Eight-year follow-up of patients with permanent vena cava filters in the prevention of pulmonary embolism: The PREPIC (Prevention du Risque d'Embolie Pulmonaire par Interruption Cave) randomized study. Circulation 112(3):416-422

45. Yavuz K, Geyik S, Hoppe H, Kolbeck KJ, Kaufman JA (2008) Venous thromboembolism after retrieval of inferior vena cava filters. J Vasc Interv Radiol 19(4):504-508

46. Jha VM, Lee-Llacer J, Williams J, Ubaissi H, Gutierrez G (2010) Adjunctive inferior vena cava filter placement for acute pulmonary embolism. Cardiovasc Intervent Radiol 33(4): 739-743

47. Food and Drug Administration (2010) Removing retrievable inferior vena cava filters: Initial communication. http://www. fda.gov/MedicalDevices/Safety/AlertsandNotices/ucm221676.htm

48. Janjua M, Younas F, Moinuddin I et al (2010) Outcomes with retrievable inferior vena cava filters. J Invasive Cardiol 22(5):235-239

49. Helling TS, Kaswan S, Miller SL, Tretter JF (2009) Practice patterns in the use of retrievable inferior vena cava filters in a 
trauma population: a single-center experience. J Trauma 67(6): $1293-1296$

50. Johnson MS, Nemcek AA Jr, Benenati JF et al (2010) The safety and effectiveness of the retrievable option inferior vena cava filter: A United States prospective multicenter clinical study. J Vasc Interv Radiol 21(8):1173-1184

51. Gaspard SF, Gaspard DJ (2009) Retrievable inferior vena cava filters are rarely removed. Am Surg 75(5):426-428

52. Zakhary EM, Elmore JR, Galt SW, Franklin DP (2008) Optional filters in trauma patients: Can retrieval rates be improved? Ann Vasc Surg 22(5):627-634

53. Kalva SP, Marentis TC, Yeddula K, Somarouthu B, Wicky S, Stecker MS (2006) Long-term safety and effectiveness of the "OptEase" vena cava filter. Cardiovasc Intervent Radiol 29(4): 559-564

54. Rimon U, Bensaid P, Golan G, et al. (epub ahead of print 6/18/ 2010) Optease vena cava filter optimal indwelling time and retrievability. Cardiovasc Intervent Radiol

55. Charles HW, Black M, Kovacs S et al (2009) G2 inferior vena cava filter: Retrievability and safety. J Vasc Interv Radiol 20(8): 1046-1051

56. Minocha J, Idakoji I, Riaz A et al (2010) Improving inferior vena cava filter retrieval rates: Impact of a dedicated inferior vena cava filter clinic. J Vasc Interv Radiol 21(12):1847-1851

57. Binkert CA, Sasadeusz K, Stavropoulos SW (2006) Retrievability of the recovery vena cava filter after dwell times longer than 180 days. J Vasc Interv Radiol 17(2 Pt 1):299-302

58. Ray CE Jr, Mitchell E, Zipser S, Kao EY, Brown CF, Moneta GL (2006) Outcomes with retrievable inferior vena cava filters: A multicenter study. J Vasc Interv Radiol 17(10):1595-1604

59. Hammond CJ, Bakshi DR, Currie RJ et al (2009) Audit of the use of IVC filters in the UK: Experience from three centres over 12 years. Clin Radiol 64(5):502-510

60. Lynch FC, Kekulawela S (2009) Removal of the G2 filter: Differences between implantation times greater and less than 180 days. J Vasc Interv Radiol 20(9):1200-1209

61. Lyon SM, Riojas GE, Uberoi R et al (2009) Short- and long-term retrievability of the Celect vena cava filter: Results from a multiinstitutional registry. J Vasc Interv Radiol 20(11):1441-1448

62. Binkert CA, Bansal A, Gates JD (2005) Inferior vena cava filter removal after 317-day implantation. J Vasc Interv Radiol 16(3): 395-398

63. Kachura JR (2005) Inferior vena cava filter removal after 475-day implantation. J Vasc Interv Radiol 16(8):1156-1158

64. Smouse HB, Rosenthal D, Thuong VH et al (2009) Long-term retrieval success rate profile for the Gunther Tulip vena cava filter. J Vasc Interv Radiol 20(7):871-878

65. Lynch FC (2011) Removal of a Gunther Tulip Filter after 3006 days. J Vasc Interv Radiol 22(3):337-340

66. Kuo WT, Tong RT, Hwang GL et al (2009) High-risk retrieval of adherent and chronically implanted IVC filters: Techniques for removal and management of thrombotic complications. J Vasc Interv Radiol 20(12):1548-1556

67. Oh JC, Trerotola SO, Dagli M et al (2011) Removal of retrievable inferior vena cava filters with computed tomography findings indicating tenting or penetration of the inferior vena cava wall. J Vasc Interv Radiol 22(1):70-74

68. Wallace MJ, Kuo MD, Glaiberman C, Binkert CA, Orth RC, Soulez G (2008) Three-dimensional C-arm cone-beam CT: Applications in the interventional suite. $\mathrm{J}$ Vasc Interv Radiol 19(6):799-813

69. Bozlar U, Edmunds JS, Turba UC, Hartwell GD, Housseini AM, Hagspiel KD (2009) Three-dimensional rotational angiography of the inferior vena cava as an adjunct to inferior vena cava filter retrieval. Cardiovasc Intervent Radiol 32(1):86-92
70. Hagspiel KD, Leung DA, Aladdin M, Spinosa DJ, Matsumoto AH, Angle JF (2004) Difficult retrieval of a recovery IVC filter. J Vasc Interv Radiol 15(6):645-647

71. Richard HM 3rd, Lowe SR, Malloy PC (2005) Retrieval of Bard recovery filter from left-sided inferior vena cava. J Vasc Interv Radiol 16(7):1039-1041

72. Pfammatter T, Hechelhammer L, Pfiffner R (2009) A "buddy wire" technique for successful OptEase filter retrieval. J Vasc Interv Radiol 20(5):656-659

73. Van Ha TG, Vinokur O, Lorenz J et al (2009) Techniques used for difficult retrievals of the Gunther Tulip inferior vena cava filter: Experience in 32 patients. J Vasc Interv Radiol 20(1):92-99

74. Lynch FC (2009) Balloon-assisted removal of tilted inferior vena cava filters with embedded tips. J Vasc Interv Radiol 20(9): $1210-1214$

75. Rubenstein L, Chun AK, Chew M, Binkert CA (2007) Loopsnare technique for difficult inferior vena cava filter retrievals. J Vasc Interv Radiol 18(10):1315-1318

76. Owens CA, Bui JT, Grace Knuttinen M, Emmanuel N, Carrillo TC, Gaba RC (2011) Difficult removal of retrievable IVC filters: A description of the "double-wire restraining" technique. Cardiovasc Intervent Radiol 34(Suppl 2):S218-S223

77. Burke CT, Dixon RG, Stavas JM (2007) Use of rigid bronchoscopic forceps in the difficult retrieval of the Gunther Tulip inferior vena cava filter. J Vasc Interv Radiol 18(10):1319-1323

78. Stavropoulos SW, Solomon JA, Trerotola SO (2006) Wallembedded recovery inferior vena cava filters: Imaging features and technique for removal. J Vasc Interv Radiol 17(2 Pt 1): 379-382

79. Stavropoulos SW, Dixon RG, Burke CT et al (2008) Embedded inferior vena cava filter removal: Use of endobronchial forceps. J Vasc Interv Radiol 19(9):1297-1301

80. Saito N, Shimamoto T, Takeda $T$ et al (2010) Excimer laserassisted retrieval of Gunther Tulip vena cava filters: A pilot study in a canine Model. J Vasc Interv Radiol 21(5):719-724

81. Kuo WT, Cupp JS (2010) The excimer laser sheath technique for embedded inferior vena cava filter removal. J Vasc Interv Radiol 21(12):1896-1899

82. Kuo WT, Odegaard JI, Louie JD, et al. (2011) Photothermal ablation with the excimer laser sheath technique for embedded inferior vena cava filter removal: Initial results from a prospective study. J Vasc Interv Radiol (in press)

83. Arabi M, Willatt JM, Shields JJ, Cho KJ, Cwikiel WB (2010) Retrievability of optional inferior vena cava filters with caudal migration and caval penetration: report of three cases. J Vasc Interv Radiol 21(6):923-926

84. Veerapong J, Wahlgren CM, Jolly N, Bassiouny H (2008) Successful percutaneous retrieval of an inferior vena cava filter migrating to the right ventricle in a bariatric patient. Cardiovasc Intervent Radiol 31(Suppl 2):S177-S181

85. Mitchell WB, Bonn J (2005) Percutaneous retrieval of a Greenfield filter after migration to the left pulmonary artery. J Vasc Interv Radiol 16(7):1013-1017

86. Turba UC, Arslan B, Meuse M et al (2010) Gunter tulip filter retrieval experience: predictors of successful retrieval. Cardiovasc Intervent Radiol 33(4):732-738

87. Yamagami T, Tanaka O, Yoshimatsu R, Miura H, Nishimura T (2010) Venous thromboembolism after removal of retrievable inferior vena cava filters. Cardiovasc Intervent Radiol 33(1): 74-79

88. Schmelzer TM, Christmas AB, Taylor DA, Heniford BT, Sing RF (2008) Vena cava filter retrieval in therapeutically anticoagulated patients. Am J Surg 196(6):944-947 